\title{
artículos
}

\section{Sofía Valera Alcalá-Galiano, duquesa de Malakoff ¿una carrera artística frustrada?}

Eva María Ramos Frendo

Universidad de Málaga

RESUMEN

El presente trabajo analiza las circunstancias que rodearon la carrera artística de una joven de la aristocracia andaluza, Sofía Valera, hermana del conocido escritor Juan Valera y hermanastra de José Freüller Alcalá Galiano, Marqués de la Paniega.

PALABRAS CLAVE: Pintura s. XIX/ Género/ Formación Artística.

Sofía Valera Alcalá-Galiano, Duchess of Malakoff, ¿an artistic career signed by frustration?

ABSTRACT

This study intends to analyse the circumstances surrounding Sofia Valera's artistic career. She was a young woman belonging to the andalusian aristocracy, Juan Valera's sister and Marqués de la Paniega's stepsister.

KEY wORDS: Painting XX th./ Genre/ Artistic Training.

Con este breve acercamiento a la vida y actividad de Sofía Valera (1828?1890) queremos presentar un ejemplo concreto que puede ser ilustrativo de lo que aconteció a otras muchas mujeres durante el siglo XIX, las cuales, poseyendo talento para la práctica de las Bellas Artes, se acercaban por mera afición y por el hecho de que dicha actividad formaba parte de la conocida "educación de adorno" de la época. Pero, más adelante, sobre todo si la fortuna familiar no era muy desahogada, podían considerar la posibilidad de utilizar esta habilidad como una futura profesión, bien dedicándose a la misma con el fin de comerciar con sus obras o, empleando sus conocimientos para la docencia de otras jóvenes.

Si finalmente se alcanzaba el ansiado estado del matrimonio, un enlace posiblemente acordado y ventajoso económicamente, veían desaparecer todas las ilusiones, convirtiéndose en unas mujeres condenadas al ámbito doméstico y al cuidado de los hijos. Pero siempre quedaría la posibilidad de volver a esta actividad, en el caso de una viudedad que dejara a la mujer en una buena posición económica, y con el tiempo necesario para volver a desarrollar su don, lo cual sería la clara prueba de una verdadera vocación truncada y retomada en el momento que las circunstancias le fueran propicias.

Esta trayectoria es la que se puede adivinar en la vida de Sofía Valera. Por lo que, aunque contando con escasos datos sobre su actividad pictórica, consideramos

* RAMOS FRENDO, Eva Ma: "Sofía Valera Alcalá-Galiano, duquesa de Malakoff ¿una carrera artística frustrada?", en Boletín de Arte, $\mathrm{n}^{\circ} 29$, Departamento de Historia del Arte, Universidad de Málaga, 2008, págs. 253-272. 
interesante exponerlos aquí. Además, el hecho de tratarse de una joven nacida en Andalucía, aunque, como veremos, más tarde alejada de nuestra región desde temprana edad, nos permite con este trabajo aportar un pequeño grano de arena que haga completar cada día más la nómina de pintoras andaluzas ${ }^{1}$. Consideramos que aunque la mayor parte de su vida, tras el matrimonio, se desenvuelve en París, la formación y práctica artística se desarrolló entre Málaga y Granada, por lo que ésta será la principal razón que nos lleva a encuadrarla como artista de esta región, a lo que se unirá también el hecho de su nacimiento.

No obstante, este esquema que hemos trazado sobre la mujer pintora en el siglo XIX no se puede considerar como el único, aunque sí el mayoritario, dado que habrá mujeres pintoras que continúen con su actividad tras el matrimonio, aunque normalmente de manera diletante, como un entretenimiento y sin buscar una salida profesional en ello².

\section{SU FAMILIA Y SUS PRIMEROS AÑOS.}

Sofía [1] nació en el seno de una familia andaluza, con título³, pero económicamente venida a menos. Del matrimonio de sus padres, José Valera y Viaña [2] (1783-1859)4 ${ }^{4}$ natural de Doña Mencía ${ }^{5}$, y Mª Dolores Alcalá Galiano [3] (1791-1872), natural de Écija (Sevilla), marquesa de la Paniega y vizcondesa del Barco, nacerán tres hijos: Juan, Sofía y Ramona6.

\footnotetext{
1 Matilde Torres López en su Tesis Doctoral La mujer en la docencia y la práctica artística en Andalucía durante el siglo XIX, defendida en Málaga el año 2007 (inédita), recoge un total de 308 pintoras andaluzas. Tras esta labor está preparando para su futura publicación un Diccionario donde se recojan dichas artistas y que se ampliará con nuevas aportaciones.

2 Nada más debemos pensar en Carmen Sánchez de Quirós, cuñada de Sofía Valera, la cual dentro del matrimonio seguirá dedicándose a la pintura, al igual que su propio esposo, José Freüller, hermanastro de Sofía. Igual sucede con Rafaela Roose de Quirós, cuñada a su vez de la citada Carmen, quien pintó durante y después del matrimonio -una vez que quedó viuda- demostrando claramente una verdadera vocación. Cfr. RAMOS FRENDO, E. Mª : El coleccionismo en la Málaga decimonónica, Málaga, (tesis doctoral inédita), 2002, págs. 143-146.

3 Su madre, Ma Dolores Alcalá Galiano, era marquesa de La Paniega, título que procedía de don Juan Alcalá Galiano y Flores de Soto, Caballero de la Orden de Santiago y le había sido concedido por el monarca Carlos III con fecha 17 de Diciembre de 1765, entrando en vigor a partir de un Real despacho realizado el 31 de ese mismo mes y año. El nombre del título hacía referencia a un caserío que era propiedad de esta familia que se encontraba ubicado en el municipio de Doña Mencía, perteneciente al partido judicial de Cabra, en la provincia de Córdoba. El título pasaría más tarde a su hermanastro José Freüller, primogénito de la madre.

4 MORENO MANZANO, J.: "Testamento del teniente de navío retirado D. José Valera y Viaña, Marqués de la Paniega", en Crónica de Córdoba y sus pueblos nº 8, 2002, págs. 37-38. Sabemos que fue Brigadier de la Real Armada, pero durante la vida de su hija pasó sus días retirado en su localidad natal dedicado a la explotación de sus fincas.

5 Encontramos otras referencias que nos indican que el nacimiento de José Valera fue en el Puerto de Santa María, aunque residiera en Doña Mencía. Cfr. VALVERDE MARDRID, J.: "En el centenario de la novela de Pepita Jiménez", Boletín de la Real Academia de Córdoba, Córdoba, 1974, pág. 37.

6 El año de nacimiento de Sofía y su hermana Ramona aparece en SANCHEZ GARCíA, Ma R.: La condición de la mujer en el intelectualismo liberal del siglo XIX: la mujer escrita en las novelas de don Juan Valera, Granada, Editorial Universidad de Granada, 2005, pág. 22. Según esta obra Sofía nacería en 1828 y sería mayor que Ramona, cuyo nacimiento tendría lugar en 1830. Según otros estudios Ramona era la segunda
} 


\section{2: artículos Sofía Valera Alcalá-Galiano duquesa de Malakoff...}
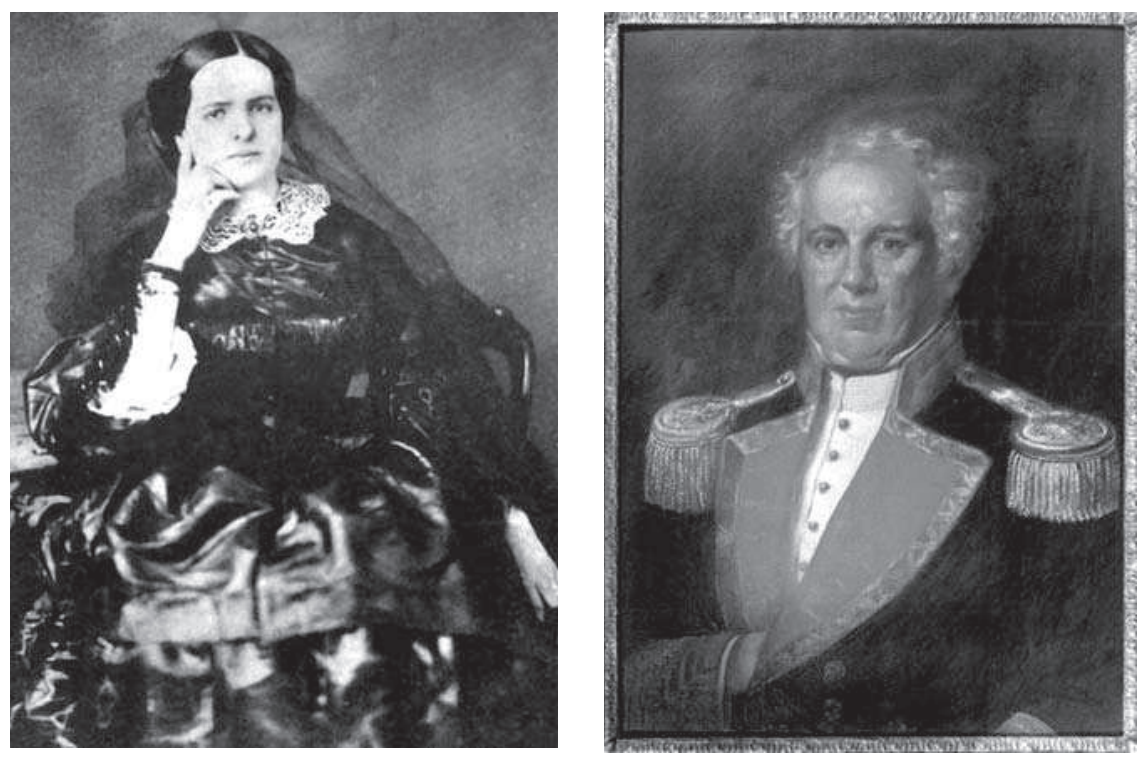

1. Fotografía de Sofía Valera. Bravo Villasante, Carmen: Biografía de don Juan Valera. 2. José Valera diplomático (1891). Enrique Romero de Torres, Sala de profesores del Instituto de Cabra.

Se trata del segundo matrimonio de la madre, quien ya tenía otro hijo de un matrimonio anterior con Santiago Freüller: José Freüller Alcalá Galiano ${ }^{7}$, quien será marqués de la Paniega tras el fallecimiento de su madre.

Sofía fue, según nos indica su hermano Juan, la hija mediana ${ }^{8}$, nacida tras el escritor y antes que Ramona, la menor de los tres. Su nacimiento tuvo lugar en Cabra, igual que su hermano Juan, donde la familia residió hacia aproximadamente 1833, marchando más tarde hacia Córdoba, luego a Madrid y finalmente a Málaga, donde el padre volvió a sus actividades de marino, primero como comandante del Tercio Naval y después de director del colegio de San Telmo ${ }^{9}$.

hija, mientras Sofía fue la menor. Cfr. SAENZ DE TEJADA BENVENUTI, C.: "Análisis de esta correspondencia”, en VALERA, J.: Cartas íntimas (1853-1897), Madrid, Taurus Ediciones, 1974, pág. 19; lo cual se contradice con las palabras de Juan Valera, como veremos más adelante.

7 En la actualidad la biografía de José Freüller, quien fuera primer presidente de la Academia de Bellas Artes de San Telmo de Málaga desde su fundación en 1850 y hasta que este falleciera en 1901, se encuentra en proceso de redacción para su posterior publicación.

8 VALERA, J.: Correspondencia, vol. II (1862-1875), Madrid, Castalia, 2003, pág. 274. En una carta escrita a Gumersindo Laverde el 6 de octubre de 1866 desde Madrid hace referencia a Sofía, por aquel entonces ya duquesa de Malakoff -título que adquirirá, como veremos más adelante, a raíz de su matrimonio- e indica: "Mi hermana mayor, la duquesa de Malakoff, ha ido a vivir a Carabanchel con la Montijo".

9 BRAVO VILLASANTE, C.: Vida de Juan Valera, Madrid, 1974, pág. 13. 


\section{Q: artículos Eva María Ramos Frendo}

Tras estos hechos, hacia el año 1847 don José Valera vivió retirado en Doña Mencía, mientras Sofía y su madre pasaban la vida entre Granada y Málaga. En la primera ciudad residió también la hermana menor, Ramona, y en Málaga tuvo su hogar el primogénito de la marquesa, José Freüller. Por tanto, vemos como la juventud de Sofía se desarrolló en diversas zonas de la región andaluza: Cabra y Doña Mencía, donde residía el padre y a donde acudirían para visitarlo en algunos periodos de tiempo, Málaga ${ }^{10}$ y Granada, aunque parece ser esta última localidad donde tuvo su residencia habitual hasta llegar al matrimonio.

Pero además, una vez que su otra hermana consiguió ascender al envidiado estado del matrimonio ${ }^{11}$, la madre realizó con Sofía abundantes visitas a Madrid, donde se encontraba su hijo Juan Valera desde que finalizara su carrera de abogado. El objetivo de estas estancias era procurar los contactos que garantizaran a Sofía un matrimonio adecuado.

La belleza con que contó la joven le proporcionó numerosos admiradores. En enero de 1847, su hermano Juan interrogaba a José Freüller sobre rumores que existían sobre amoríos de su hermana:

"Da expresiones a mamá y a mi hermanita Sofía, de quien te ruego me escribas qué hay de sus amores con el descendiente del jefe de los comuneros. Aquí me han dado la noticia de que se casa, y añaden que Padilla ha ido a Málaga por ella; dime qué hay en esto de verdad"12.

\section{SU VIDA EN MADRID.}

En Madrid Sofía se codeó con familias de las más destacadas. Sobre todo, tanto su madre como ella mantuvieron una gran amistad con la condesa de Montijo, doña María Manuela Kirkpatrick (Manuela de Guzmán a raíz de su matrimonio con don Cipriano Guzmán Palafox y Portocarrero). Ma Manuela había nacido en Málaga, al haberse establecido su padre, un negociante escocés, en dicha localidad, donde se dedicó a comerciar con vinos y ostentó el cargo de cónsul de los Estados Unidos $^{13}$. No sabemos si dicha amistad entre la condesa de Montijo y la marquesa de la Paniega surgiría al coincidir ambas en la localidad malagueña o se desarrollaría por otras circunstancias. Pero lo que sí podemos asegurar es que la misma fue decisiva en la vida social de Sofía y para su futuro.

Desde que en 1834 falleciera don Eugenio Guzmán Palafox, hermano del marido de $\mathrm{M}^{a}$ Manuela, ésta y su esposo pasaron a heredar el título de condes de Montijo

\footnotetext{
10 En enero de 1847, por carta de Juan Valera, sabemos que mientras Ramona y su esposo están en Granada, Sofía está con su Madre en Málaga, con José Freüller. VALERA, J.: Correspondencia, vol. I (18471861), Madrid, Castalia, 2002, pág. 37.

11 Ramona se casa con Alonso Mesía de la Cerda, marqués de Caicedo hacia 1847.

12 VALERA, J.: Correspondencia, vol. I...op. cit., pág. 38.

13 CABAL, J.: La Emperatriz Eugenia de Montijo, Barcelona, Juventud, 1960, pág. 8.
} 


\section{Q: artículos Sofia Valera Alcalá-Galiano duquesa de Malakoff...}

y todas las propiedades del difunto. Mas será a partir del fallecimiento de Cipriano Guzmán, en 1839, cuando se iniciará la importante vida social de la condesa y sus hijas, Francisca y Eugenia Montijo, la primera futura duquesa de Alba, a raíz de su matrimonio con don Jacobo Luis Stuart Fitz y la segunda condesa de Teba y Emperatriz de los franceses tras su enlace con Napoleón III.

Tanto en su palacete de Madrid, ubicado en la plaza del Ángel, como en la finca de recreo de Carabanchel se iniciaron continuas tertulias, representaciones teatrales o musicales y bailes a los que asistiría lo más destacado de la aristocracia, miembros de la política y escritores ilustres ${ }^{14}$, entre ellos Juan Valera. A estos eventos, cuando estaba en Madrid, también acudía Sofía con su madre.

Sofía se convirtió en una de las jóvenes que más atracción producían en el género masculino, dentro de estas reuniones en la Corte,

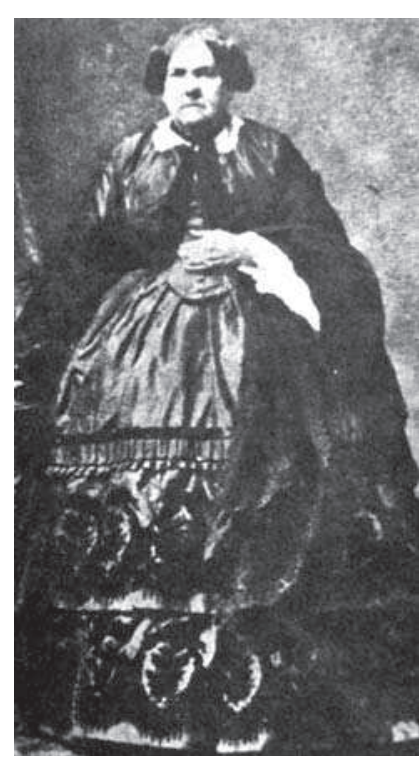

3. $M^{a}$ Dolores Alcalá Galiano. pues además de otras muchas cualidades que debía tener, se destacó por poseer una "belleza espléndida"15. Su éxito la llevó a recibir interesantes ofertas que ella rechazaba ante la falta de un verdadero amor. De esta manera, en febrero de 1850, su hermano Juan escribía a su padre y le exponía el orgullo que sentía de que su hermana hubiera rechazado una proposición de matrimonio con Villalegre:

"Me alegro tanto de que mi hermana Sofía no forme proyectos interesados sobre Villalegre, porque esto la honra mucho... si se casara con él, todas las señoritas la envidiarían; pero esto no prueba más sino que en el día las señoritas y los señoritos, y en general todo el mundo, no atienden sino al interés y hacen poco caso de la dignidad humana, de los grandes sentimientos, etc. Yo espero que Sofía será más feliz con su orgullo y sin marido rico, que rica pero avergonzada con un marido borrico" 16 .

Sofía será también protagonista en muchas de esas representaciones aristocráticas que se desarrollaban en Carabanchel y la misma prensa dejó constancia de su presencia [4].

14 Ibídem, págs. 12-21.

15 MONTECRISTO: "Madrid Elegante", en Álbum Salón, 16-01-1899, pág. 28.

16 VALERA, J.: Correspondencia, vol. I...op. cit., pág. 75. 


\section{Q: artículos Eva Maria Ramos Frendo}

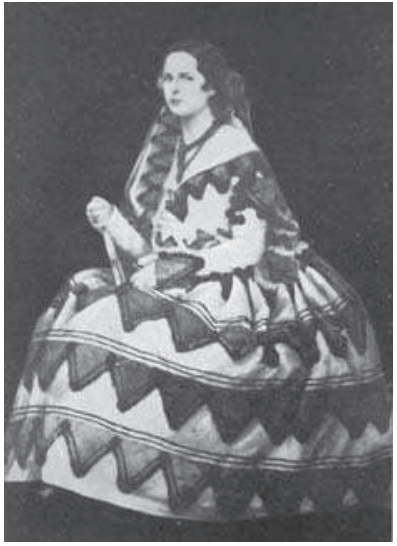

4. Sofía Valera vestida de gitana para un baile en casa de la condesa de Montijo. La Esfera $\mathrm{n}^{\circ} 570,6-12-1924$

Así en septiembre de 1856 se nos relataba todo lo concerniente a una función aristocrática desarrollada en el teatro existente en la finca de recreo, descrito por Félix de Llanos y Torriglia como "...el tinglado de la farsa"17, una construcción ubicada en uno de los rincones del parque de la finca. En esta ocasión las distintas representaciones se realizaron con motivo del cumpleaños de la condesa. Sofía tomó parte de la zarzuela Buenas noches, señor don Simón junto con otros miembros de la alta sociedad. Además representaciones teatrales y ópera completaron el evento, desarrollado en un escenario que fue elogiado por su perfecto arreglo. Para finalizar, los invitados se trasladaron al palacete (edificación de dos pisos con torreón en el centro al que se accedía desde un patio cuadrado con fuente central) donde disfrutaron en la sala de baile de dulces y helados, continuando el festejo hasta bien entrada la madrugada ${ }^{18}$.

Un año más tarde, en agosto de 1857, volvemos a contar con noticias de otro nuevo encuentro de miembros de la aristocracia en la finca de Carabanchel, donde en esta ocasión Sofía formó parte de una representación teatral de la pieza Por un reló y un sombrero junto con los duques de Alba y los señores Álvarez de Sotomayor, Murillo, Merri y Vejarano ${ }^{19}$.

Tal debió ser el protagonismo de Sofía que años más tarde cuando la prensa recordaba con añoranza los salones aristocráticos del Madrid del siglo XIX y la belleza de sus mujeres aludía a la misma junto con Eugenia de Montijo y María Bushental20.

\section{LA ACTIVIDAD PICTÓRICA DE SOFIA.}

Y será concretamente durante dichos años en que su vida se debate entre Granada y Madrid, cuando tengamos noticias de sus actividades pictóricas, además de otros avances e inquietudes intelectuales ${ }^{21}$. Su hermano Juan se convierte, a través de su correspondencia, en el principal cronista de la vida de su hermana, bien en cartas a su madre o directamente en los escritos que remite a Sofía.

\footnotetext{
17 CABAL, J.: La Emperatriz... op. cit., pág. 23.

18 La Iberia, 19-09-1956.

19 La Iberia, 04-08-1957.

20 MONTECRISTO: op. cit., pág. 28

21 Las primeras noticias de su actividad nos llegan hacia 1850.
} 
En octubre de 1850, mientras Juan Valera se encuentra residiendo en Portugal como agregado de número de la Legación de Lisboa, escribirá a su madre indicándole su alegría al saber que su hermana Sofía estaba dedicándose a estudiar "historia y otras cosas útiles y buenas, que hagan su alma más grande que la fortuna" 22 . Una semana más tarde escribiría en esta ocasión a Sofía y mostraría un gran interés por su actividad artística al preguntarle acerca de los cuadros que estaba pintando 23 .

Por tanto es de suponer que por estas fechas la joven ya debía de contar con una cierta formación en el arte de la pintura. El aprendizaje se desarrolló en Granada donde, por lo que deducimos de los escritos de su hermano, contó con la ayuda de un profesor particular que la orientó en dicha actividad, lo cual era lo habitual en esta época en el caso de jóvenes de clase alta que podían costear dicha enseñanza que se solía desarrollar especialmente en el hogar. También cabe la posibilidad que dicho pintor impartiera clases para señoritas en su estudio, pero carecemos de datos al respecto, considerando más probable la primera hipótesis expuesta.

Este docente fue el pintor italiano Andrés Giuliani y Cosci24 (1815-1889), el cual sería algunos años después director de la Escuela de Dibujo que en 1838 se había creado en Almería, obra impulsada por la Diputación Provincial de dicha ciudad, y maestro de algunos de los más afamados pintores almerienses como José Díaz Molina, Antonio Bedmar o Manuel Luque.

La labor docente que desempeñó con Sofía debió ser previa, durante los años en que Giuliani estuvo establecido en Granada -como atestigua la presencia de obras de su mano entre los fondos de la Universidad granadina-25 dado que su estancia en Almería, por lo que deducimos de las obras que realizó para el Ayuntamiento de dicha localidad, data de 185926 , cuando Sofía ya había contraído matrimonio y abandonado nuestro país.

En enero de 1851, Juan Valera indicaba en carta a su padre que Sofía había realizado una copia de un retrato suyo que poseía de mano del pintor Giuliani27. Posiblemente el retrato original de Giuliani sea la obra que se conserva en la Capellanía de los Valera en Doña Mencía y que aparece bajo el título de "Retrato romántico de Juan Valera joven" [5], un retrato de tres cuartos del escritor y con un

22 VALERA, J.:Correspondencia, vol. I...op. cit., pág. 120.

23 Ibídem, pág. 123. La carta es del 14 de octubre de 1850

24 En colección particular malagueña de descendientes de la familia Alcalá Galiano se conserva un retrato firmado por Giuliani que representa un autorretrato del pintor junto con el retrato de Sofía lo que afianza aún más la relación entre la joven y el pintor.

25 Hacia finales de octubre de 2006 se organizó una exposición en el crucero del Hospital Real de Granada, que se mantendría hasta el 17 de enero de 2007, donde se exponían las Obras Maestras del Patrimonio de la Universidad de Granada. Entre dichas obras, que abarcaban desde el siglo XVI hasta el siglo XX, se encontrarán algunas de la mano del citado pintor.

26 Las noticias sobre este pintor las hallamos en CAPARROS MASEGOSA, Ma D.: La pintura almeriense durante la época de la Restauración, Granada, Universidad de Granada, 1997, págs. 32 y ss.; NICOLÁS MARTÍNEZ, Ma M.: "La pintura almeriense del periodo fin de siglo. Problemática y estado de la cuestión" en ROZALÉN FUENTES, Celestina, UBEDA VILCHES, R. Ma (coord.): La crisis de fin de siglo en la provincia de Almería: el desastre del 98, Almería, 2004, págs. 303 y 306-307.

27 VALERA, J.: Correspondencia, vol. I...op. cit., pág. 129. 


\section{Q: artículos Eva Maria Ramos Frendo}
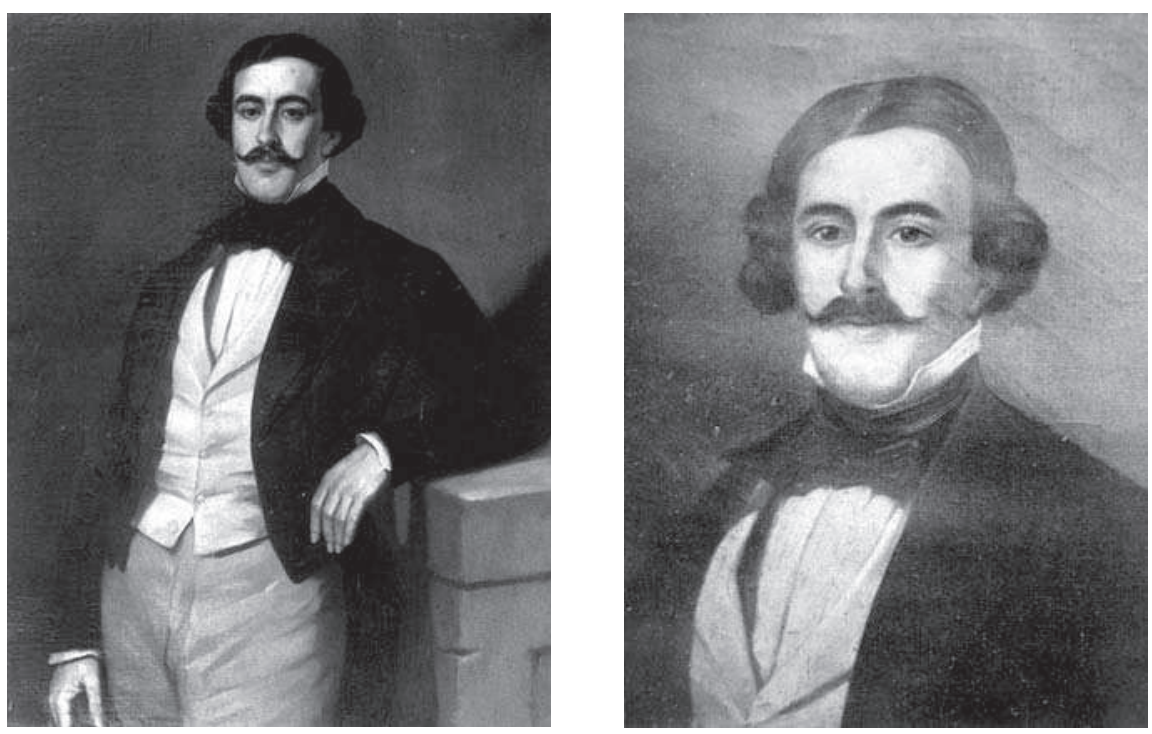

5. "Retrato romántico de don Juan Valera de joven", Exposición Juan Valera 85 aniversario de su muerte (1990), Capellanía de los Valera en Doña Mencía.

6. "Don Juan Valera”, retrato al óleo de Sofía Valera, La Esfera n 570, 6-12-1924.

atuendo elegante a la inglesa, llevando la camisa blanca de cuello recto y puntas hacia las mejillas, sujeta con un pañuelo, chaleco también blanco, sobre el que se dispone una sencilla chaqueta negra de faldones cortos y, como era habitual en la moda de la época, los pantalones de distinto color, en este caso de una tonalidad anaranjada. El resultado es una imagen que claramente nos lleva a la representación de un respetable burgués ${ }^{28}$, cuyo rostro presenta un cuidado bigote y que carece de sombrero por encontrarse en el interior.

Sobre la copia realizada por Sofía, que Juan expresaba que no dudaba estaría bien hecha ${ }^{29}$, tenemos una imagen publicada en la revista La Esfera en noviembre de 1924 [6]. Esta imagen nos muestra con total claridad que se trata de una copia de la obra anteriormente citada como obra de Giuliani, aunque tan sólo presenta un busto largo y no la totalidad de la obra del italiano. No sabemos si esto se debe a que Sofía copió sólo parte de dicho retrato o por el contrario si es la reproducción de la revista la que nos muestra parcialmente la obra de la joven. La calidad es inferior a la del pintor italiano, mostrando así los progresos de una joven que se estaba iniciando en el arte de la pintura.

28 LAVER, J.: Breve historia del traje y la moda, Madrid, Cátedra, 1997, págs. 162-1644 y 170-172.

29 VALERA, J.: Correspondencia, vol. I...op. cit., pág. 129. 
Esta copia del retrato de Juan Valera era un regalo para su padre Juan Valera quien, como nos expresa el escritor en carta a su madre, recibió dicha obra en Doña Mencía y quedó sumamente contento con el resultado ${ }^{30}$.

En estos años en que Sofía está formándose como pintora no existía en la ciudad granadina un establecimiento que le garantizara una adecuada formación, dado que la Clase de dibujo para señoritas que desde enero de 1788 había existido, vinculada a la Sociedad Económica de Amigos del País de Granada y a partir de 1808, a la Academia de Nuestra Señor de las Angustias; desde 1849 había paralizado su funcionamiento debido a la pérdida de categoría de la Academia, que pasaba de considerarse de primera clase a segunda. La citada clase destinada a la formación de la mujer pasó a depender nuevamente de la Sociedad Económica y no se reinició hasta febrero de $1856^{31}$, fecha en la que Sofía ya llevaba algunos años ejecutando la pintura. Por todo esto, cuando la escuela para señoritas entra en su apogeo ya nuestra biografiada se ha alejado definitivamente de Granada.

Estas obras que Sofía fue pintando, dado su categoría de principiante, unido a su condición de mujer, no fueron destinadas a la venta, puesto que la profesionalización de esta actividad en mujeres no estaba bien vista en el siglo XIX ${ }^{32}$. Únicamente, cuando la economía familiar y la falta de un matrimonio obligaban a la mujer a ganarse la vida, podía la pintura considerarse un medio respetable ${ }^{33}$, pero más si cabe la docencia de la misma a otras señoritas.

Sofía en los años en que se está formando aún no ha perdido la esperanza (ni su familia tampoco) de encontrar un marido adecuado, por lo que la pintura se convirtió en principio en una actividad que contribuía a darle más brillo y fama entre los miembros de la Corte madrileña.

Así, en enero de 1850, Juan Valera escribía a su madre y le expresaba que en casa de la condesa de Montijo ( $\mathrm{M}^{\mathrm{a}}$ Manuela) había hablado con el barón del Solar de Espinosa y éste le había comunicado que era un gran apasionado de su hermana Sofía ${ }^{34}$. Éste debía ser don Jacobo Ma Espinosa y Quintana, Senador vitalicio por la provincia de Valencia, secretario del Estado, ministro de la Guerra y Teniente General del Ejército, el cual en aquellos momentos debía tener unos 57 años de edad $^{35}$. Desconocemos a que tipo de pasión se refería Juan, si en relación a su talento como pintora o, por su hermosura y belleza como mujer. Más nos inclinamos a pensar que era la primera de las expuestas, dado que este noble caballero había adquirido una obra pictórica de Sofía que tenía expuesta en su domicilio. En febrero de 1850 el hermano de la joven comentaba a su madre lo siguiente:

\footnotetext{
30 Ibídem, pág. 133

31 TORRES LÓPEZ, M.: La mujer en la docencia y la práctica artística en Andalucía durante el siglo XIX, Málaga (tesis doctoral inédita), 2007, págs. 268-270.

32 DIEGO, E. de: La mujer y la pintura del XIX español, Madrid, Cátedra, 1987, pág. 18.

33 Situación que se dio en Francia tras las guerras napoleónicas. Ibídem, pág. 67.

34 VALERA, J.: Correspondencia, vol. I...op. cit., pág. 65.

35 (A)rchivo del (S)enado: Sig. HIS-0446-03, Expediente personal del Senador Barón del Solar de Espinosa,

D. Jacobo María Espinosa, por la provincia de Valencia y vitalicio.
} 


\section{Q: artículos Eva Maria Ramos Frendo}

"En casa del amabilísimo, tontísimo y espetadísimo barón del Solar he visto, aunque mal, porque no llevaba lentes y estaba muy alto, un cuadro de Sofía, que me ha parecido muy bonito y excitado el deseo de tener algo del mismo autor para que adorne mi cuarto" 36 .

Por lo que aquí expresa Juan Valera y veremos en otros escritos posteriores, las obras pictóricas que normalmente realizaba Sofía eran copias de cuadros de artistas de reconocido prestigio, algo que era lo más habitual en la época y que muchas coetáneas criticaban, pues les impedían llegar a crear composiciones propias. Dentro de estas copias, como hemos expuesto anteriormente, también realizó Sofía la de retratos de miembros de su familia, en este caso de un artista no especialmente destacado. Desconocemos si más adelante se atrevió a realizar retratos familiares directamente, sin recurrir a copiar otros ya existentes.

Mas su hermano Juan, que tan duro fue con otras mujeres de su época, tuvo un trato totalmente diferente con el futuro de su hermana y será durante estos años su principal consejero en lo que a la práctica del arte se refiere. Juan quería ante todo que su hermana estudiara, a fin de que llegara a ser una buena artista. La profesionalización de la misma no la descartaba, puesto que, como expresaba, una vez estuviera preparada podría con la pintura "...ganar honra y dinero"37. Juan tenía muy claro ese futuro de su hermana y lo exponía a su padre con estas palabras:

"Entonces, (es decir, cuando estuviera ya totalmente formada y preparada), en vez de ser indecoroso vender sus cuadros, redundará en gloria suya, y tan hermosa posición podrá conquistar su talento, que nada tendrá que envidiar a las duquesas y a las más grandes señoras. Pero el vender ahora sus cuadros, que no son más que copias, y ocultando el nombre de la autora, me parece feo y que no puede producir sino mezquinísimo provecho, dado caso que lo produzca"38.

Estas palabras las escribía Juan Valera en enero de 1851, cuando aún era totalmente consciente de las carencias de su hermana, mas tenía total convencimiento en el talento que ésta poseía y, dadas las carencias formativas de la época, él se dedicaba en estas cartas a asesorar a los miembros de su familia acerca de lo que Sofía debía hacer para adquirir una adecuada preparación.

Para Juan Valera su hermana no sólo debía dedicarse a realizar dibujos y pinturas, copiando de obras de otros artistas con el fin de ir practicando, sino que también tenía que estudiar sobre teoría del arte, anatomía externa, perspectiva, estética y vidas de pintores. Estos conocimientos debía adquirirlos a través de las mejores obras que se hubieran publicado en esos momentos. Además de la copia, también le indicaba que copiara del natural, posiblemente se está refiriendo a la realización

36 VALERA, J.:Correspondencia, vol. I...op. cit., pág. 72.

37 Ibídem, pág. 130.

38 Ibídem. 
2: artículos Sofía Valera Alcalá-Galiano duquesa de Malakoff...

de paisajes, flores y bodegones, temas habituales entre las mujeres de esta época.

Las lecturas sobre arte debían complementarse con otras sobre historia, poesía y demás temas, a fin de "...cultivar y fecundar su ingenio". Todo lo hasta aquí expuesto conduciría al fin último que era que Sofía llegara a atreverse a "....inventar y componer"39. Es decir, salir de ese copismo continuo que se denunciaba en la época y crear obras propias. De ahí que su hermano, consciente de uno de los grandes males de la enseñanza femenina pictórica de la época, el no poder estudiar la figura humana, le aconseje las obras sobre anatomía, buscando así paliar esa carencia.

Otros destacados aristócratas de Madrid también contaron con obras realizadas por Sofía, especialmente la condesa de Montijo y Teresa Casa Valencia. La primera, Manuela de Guzmán también se había destacado por pintar, además de cantar, bailar y representar comedias 40 . El entregar obras a estas damas no sabemos si se debió a petición de las mismas o por mediación de su hermano que se habría dedicado a exaltar ese talento de su hermana. Todo formaba parte del plan de Juan Valera, pues si Sofía regalaba sus obras a estas señoras, las mismas las enseñarían al resto de la aristocracia madrileña, contribuyendo así a publicitar el talento de esta joven. Se valoraría principalmente el hecho de que Sofía hubiera alcanzado un buen hacer en un lugar como Granada donde, como ya hemos mencionado, existían escasos medios para una adecuada preparación. Indiscutiblemente la formación en Madrid, donde se contaba con obras de gran categoría en el Museo del Prado o en otras muchas colecciones de la aristocracia de la capital, facilitaba al menos la labor de la copia de obras de calidad, no siendo igual en otras localidades.

Juan exhortó a su padre, en esta carta del 8 de enero de 1851, en la que la mayor parte de su extensión se centraba en la carrera artística de Sofía, para que su hermana desarrollara en aproximadamente nueve meses un intenso trabajo de preparación a fin de presentar una obra original e íntegramente de su mano ${ }^{41}$ en la Exposición de Madrid42 o, en caso de que no fuera capaz, al menos una copia del mejor y más dificultoso cuadro que existiera en Granada de un pintor conocido. Esta sería otra forma de publicitar su talento, pues tras las exposiciones la prensa y los entendidos elogiaban las obras más destacadas. Para golpe final, Juan pretendía que el cuadro que realizara su hermana fuera regalado a la Reina, quien nombraría así a su hermana pintora de cámara o algún otro cargo que le daría la suficiente fama para ser requerida por toda la alcurnia de Madrid y realizarles retratos o cuadros de otras temáticas. Desconocemos si esta obra llegó a presentarse, pero aunque no fuera así, con las obras que repartió entre las élites de la época, tuvo indis-

39 Ibídem.

40 CABAL, J.: La Emperatriz... op. cit., pág. 9.

41 Juan indicada a su padre: "pero sin que le ayude Giuliani, sino con consejos.". Cfr. VALERA, J. Correspondencia, vol. I...op. cit., pág. 130

42 Desconocemos a que exposición se refiere, dado que las Exposiciones Nacionales de Bellas Artes se iniciarían unos cinco años más tarde en 1856. GUTIÉRREZ BURÓN, J.: Exposiciones Nacionales de Pintura en España en el siglo XIX, Madrid, Universidad Complutense, 1987 y PANTORBA, B. de: Historia y crítica de las Exposiciones Nacionales de Bellas Artes celebradas en España, Madrid, 1980. 
cutiblemente una exposición pública de sus obras.

Resulta curioso ver como Juan Valera (años más tarde, en 1891, participaría en la polémica conocida como "cuestión académica" al tratar la incorporación de las mujeres a dicha institución, donde se enfrentó a la escritora Emilia Pardo Bazán) ${ }^{43}$ se muestre aquí tan sumamente moderno cuando está tratando de temas relacionados con su hermana. Juan estaba totalmente convencido de que su hermana, si no en un año, en dos, tres o cuatro lograría un brillante porvenir y llegaría, según sus propias palabras, "... a ser un pintor" 44 . La gran pena de Juan era la falta de fortuna en la familia, lo que impedía poder llevar a Sofía a viajar por Italia, donde podría entrar en contacto con los más destacados monumentos de la antigüedad. El citaba como lugares de destino Roma, Nápoles y Florencia. Y es posiblemente esa dificultad económica lo que le hace desear que su hermana esté preparada para el caso de que pudieran caer en un estado de verdadera necesidad.

De hecho, al deseo de que su hermana se prepare, se une el de que la familia pueda vivir en Madrid de una forma decente, lo que abriría más posibilidades a Sofía para prosperar como artista o para conseguir un matrimonio adecuado. Por ello, durante el verano de 1850, esperaba el éxito político de su padre, siendo elegido diputado, para de esa manera garantizar una mayor prosperidad a su esposa e hija y permitirles venirse a vivir a Madrid de forma definitiva, pues en dicha ciudad, "...con el sueldo de brigadier que le pagaran corrientemente y con lo de Doña Mencía, podrán vivir con desahogo y decencia" 45 .

No obstante, todo este deseo de un buen casamiento para Sofía era siempre y cuando dicho enlace fuera con alguien apreciado por ella, no sólo por el interés y así Juan expone los siguientes deseos:

"Hará bien Sofía en no casarse como no halle un hombre que le guste mucho" 46 .

“...Sofía que no está casada, ni yo deseo que se case en la vida, como no sea con un hombre que por todos estilos la merezca" 47 .

En otra carta que Juan envió a su hermana le pedía que le remitiera a Lisboa, donde el estaba destinado en esos momentos, una obra titulada "Los Reyes Magos", mas no nos da ningún dato del autor. Suponemos que igual que en otros casos debe tratarse de una copia. También aprovecha para reprender a la hermana, pues no había enviado aún un cuadro prometido "...a la Montijo". De este modo nos nombra Juan a la destinataria de dicha obra, no sabiendo si se refiere a la condesa de Montijo

43 DIEGO, E. de: Op. cit., págs. 210-213.

44 VALERA, J.: Correspondencia, vol. I...op. cit., pág. 130.

45 Ibídem, pág. 108. Al hablar de Doña Mencía, localidad donde los padres de Juan y Sofía tenían propiedades y de donde procedía el título ostentado por la madre, Marquesa de la Paniega, se debe referir a las ganancias que las explotaciones que poseían les podrían reportar.

46 Ibídem, pág. 133.

47 Ibídem, pág. 134. 
en esos momentos, $M^{\mathrm{a}}$ Manuel de Guzmán o a una de sus hijas, Eugenia, la futura Emperatriz de Francia, dado que poco después le indica a la hermana lo siguiente: "Cuando al cabo se lo mandes, si llegas a mandarlo, escríbele a Eugenia que quisiste sacar copia y que por eso tanto tiempo se ha detenido en tu poder"48.

Igualmente, también le ruega que envíe a Teresa Casa Valencia otra de sus obras, pues dicha señora le había pedido un cuadro. Juan le indica que sea uno de los más bonitos que tenga y si no considera que ninguno sea adecuado, que pinte uno nuevo. Finalmente le vuelve a dar los mismos consejos que ya expusiera anteriormente a los padres, con el fin de que la preparación que adquiera le sirva para adquirir en la Corte el "predicamento de profesora" 49 . Como ejemplo que sirva de estímulo a su hermana le cita a Rosario Weiss, la cual se dedicó sobre todo a realizar copias y retratos a lápiz y, sin embargo, acabaría siendo la maestra de dibujo de Isabel II y su hermana, la infanta doña Luisa Fernanda ${ }^{50}$. Finalmente, le vuelve a insistir en que forme grupos con modelos y comience así a componer obras y además, que le pida a él aquellos libros que sean necesarios para su formación y que deban traerse de Madrid51.

En agosto de 1851 nos llegan las últimas noticias sobre Sofía como pintora, cuando Juan expone a su madre el deseo de saber el efecto que produce en Madrid el cuadro realizado por Sofía para Teresa de Casa Valencia52. No se nos indica si la obra fue un original o copia, lo que sí sabemos es que, no considerando adecuada ninguna de las que ya poseía, Sofía se decidió a realizar una nueva pintura para entregar a dicha señora.

En la correspondencia posterior aludirá a su deseo de que Sofía luzca en Madrid su gracia, talento y hermosura y para ello realiza un plan que haga posibles largas estancias de la joven en la corte. Éste consistiría en la venta de la casa de Granada, para marchar a Cabra, donde ahorrarían dinero durante un año, para en septiembre del año siguiente (1852) marchar a Madrid, donde pasarían parte del año (desde octubre hasta cuaresma) y el resto en Cabra53.

Además de las noticias que nos han podido llegar a través de la correspondencia de Juan Valera, también otros datos nos los proporcionan los documentos notariales. En esta época, como hemos podido ir viendo a lo largo de lo expuesto, uno de los principales destinos de las obras de arte realizadas por las jóvenes sería servir de decoración a su domicilio o a los de sus familiares. La obra de estas aficionadas sería utilizada como regalo para los amigos y seres más allegados.

Sofía, como hemos expresado, tenía un hermano mayor (hermanastro, por ser hijo de su madre y el primer esposo de ésta), José Freüller, que residía en Málaga. Éste, al igual que su esposa Carmen Sánchez de Quirós, también eran afi-

48 Ibídem, pág. 140

49 Ibídem.

50 ÁLVAREZ LOPERA, J.: "La carrera de Rosario Weiss en España: a la búsqueda de un perfil" en VIII Jornadas de Arte. La mujer en el arte español, Madrid, Editorial Alpuerto, 1997, págs. 309-324.

51 VALERA, J.: Correspondencia, vol. I...op. cit., pág. 141.

52 Ibídem, pág. 173.

53 Ibídem, pág. 177. 
Q: artículos Eva Maria Ramos Frendo

cionados a la pintura y en algunas ocasiones Sofía con su madre pasarán largas temporadas con ellos en la capital malacitana. Allí Sofía también deleitará a la burguesía con sus dotes artísticas y tenemos constancia de la existencia de una obra de su mano que representaba en miniatura la imagen de "El Salvador". Dicha obra estaba en poder de Mercedes Sánchez de Quirós, una de las hermanas de la mujer de José Freüller. Mercedes al realizar testamento dispuso que la miniatura fuera entregada a su cuñado ${ }^{54}$, segura de que al ser de manos de su hermana, el estaría muy orgulloso de conservarla. Es de suponer, aunque carecemos de datos que lo confirmen, que si Sofía entregó pinturas a miembros de la familia Sánchez de Quirós, con total seguridad también regalaría piezas de su mano a su hermanastro José Freüller y a su cuñada, pero la documentación existente de los bienes de ambos no dejan ningún dato sobre alguna obra de arte de la joven Sofía.

\section{EL FIN DE UNA PROMETEDORA CARRERA ARTÍSTICA.}

Hacia 1855 parece ser que se produjo el fin de esta carrera artística o, al menos, la ausencia de noticias por parte de Juan Valera al respecto de la misma. $Y$ hablamos de una artista prometedora partiendo de los comentarios poco objetivos que nos realiza su hermano, por lo que lo mismo el escritor vio un talento en su hermana que a lo mejor no era tal, pero la falta de obras o de otras opiniones nos impiden tener otros datos al respecto. No obstante, el hecho de que miembros de la Corte madrileña también decoraran sus mansiones con obras de la joven, es otro dato que nos hace suponer un cierto talento o, quizás, un enorme afecto hacia la misma. La verdad, dada la carencia de piezas de su mano, no nos puede ser revelada.

En este año Sofía ya se traslada con su madre a Madrid. Allí la vida se desarrollará entre la casa de su hermano y las residencias de la condesa de Montijo, donde Sofía acude en numerosas ocasiones como invitada. Ya años atrás la joven había cultivado una gran amistad no sólo con la condesa sino también con su hija Eugenia, como le relataba $\mathrm{M}^{\mathrm{a}}$ Dolores Alcalá Galiano a su hijo Juan Valera, el cual le rogaba a su madre en cartas posteriores: "Sígame Vuestra Merced contando los progresos de la amistad y cariño entre mi hermana y Eugenia"55. Tal fue la amistad que le unió a las Montijo que al hablar la prensa de Sofía, tras su fallecimiento, indicaba que era la "...amiga y parienta de la emperatriz Eugenia" 56 e incluso más adelante exponía que era la prima de Eugenia de Montijo, cuando, como sabemos, no hubo relación de parentesco entre ambas, sino una gran y estrecha amistad.

En agosto de 1856 Juan escribía a su hermano José Freüller indicándole que Sofía estaba en Carabanchel, donde disfrutaba de numerosos bailes y de comedias de aficionados, algunas de las cuales eran recogidas por la prensa de la época.

54 (A)rchivo (H)histórico (P)rovincial de (M)álaga, Escribanía de don Miguel Cano de la Casa, leg. 5048, 1861, Testamento de doña Mercedes Sánchez de Quirós, fols. 289v.-304.

55 VALERA, J.: Correspondencia, vol. I...op. cit., pág. 105.

56 La llustración Española y Americana, 30-11-1890, pág. 326. 
2: artículos Sofía Valera Alcalá-Galiano duquesa de Malakoff...

También fueron frecuentes las visitas al Palacio Real, indicando Juan Valera, también en agosto de 1856, la asistencia a un baile que se celebró para festejar la futura boda de la infanta ${ }^{57}$ (no sabemos a quien se refiere, pues ni Isabel II ni Luisa Fernanda contrajeron matrimonio en dicho año).

La amistad de Sofía con los Montijo fue decisiva en su futuro. Hacia 1856, cuando hacía ya tres años que Eugenia había contraído matrimonio con Napoleón III, Sofía acompañó a la condesa de Montijo (la madre de ésta) en un viaje a París para visitar a su hija. Durante esta estancia se produciría un compromiso entre Sofía y el barón de Rostchild, lo que inmediatamente fue difundido por la prensa. El diario La Iberia se hacía eco de rumores que estaban produciéndose en París acerca del futuro enlace de Sofía Valera con el barón de Rostchild58. Además exponían que si dicho enlace era cierto, Sofía podía convertirse en dama de la emperatriz Eugenia. Días más tarde se indicaba que ya uno de los colaboradores, Pedro Fernández, había anunciado, al comentarse el viaje de Sofía a París, que la joven andaluza causaría sensación en la corte de Napoleón III59.

Este barón debía de tratarse de un miembro de esta dinastía de banqueros y financieros de origen judeoalemán de gran influencia en toda Europa durante el siglo XIX. Es posible que se refiera a James, el que fuera el menor de los cinco hijos del fundador de la dinastía, dado que el Emperador de Austria nombró barones en 1822 a los cinco hermanos Rostchild. Mientras los otros cuatro fallecieron con anterioridad a la fecha en que se producía esta visita de Sofía a París, James lo haría en 1868. Dados los numerosos negocios de esta familia, con sucursales en diversas ciudades de Europa, entre ellas París, no es de extrañar que contactara allí con Sofía durante la estancia de la misma.

De esta noticia de compromiso no aparece ninguna referencia en la correspondencia de Juan Valera, mientras que algunos meses después, cuando marcha a San Petersburgo con el duque de Rivas, sí hace mención a un intercambio de cartas entre éste y su hermana Sofía 60 . Por tanto, de ser cierto este compromiso, no sabemos qué pudo producirse con posterioridad o si quizás se trató de un error de la prensa de la época.

Será dos años después, hacia agosto de 1858, cuando se inicien las noticias del futuro enlace de Sofía Valera con Aimable Jean Jacques Pellissier (en la prensa nos aparece como Pellissier), duque de Malakoff y Mariscal de Francia, quien combatió como Comandante del primer cuerpo de los ejércitos franceses en la guerra de Crimea. Su toma en 1855 de la Torre de Malakoff provocó la caída de Sebastopol. A raíz de esta victoria le sería otorgado el título de duque de Malakoff61 y el de

57 VALERA, J.: Correspondencia, vol. I...op. cit., pág. 322.

58 La Iberia $\mathrm{n}^{\circ} 538,09-04-1856$.

59 La Iberia n $542,14-04-1956$

60 VALERA, J.: Correspondencia, vol. I... op. cit., págs. 374-375.

61 La Iberia, 13-01-1857. En este día la prensa nos anunciaba que el Emperador Napoleón III había concedido el título de duque al general Pellicier con 6.000 francos de renta. Juan Valera, en carta escrita a su hermano José indica que el duque tiene 40 mil duros de renta y 100 mil duros de sueldo. VALERA, J.: Correspondencia, vol. I... op. cit., pág. 581. 


\section{2: artículos Eva María Ramos Frendo}

Mariscal de Francia; se convirtió en el brazo derecho del Emperador de Francia.

Tras este vínculo estuvo claramente la mano de la condesa de Montijo ( $\mathrm{M}^{\mathrm{a}}$ Manuela), gran favorecedora de la joven, la cual siempre había destacado por sus habilidades en "...el arte de juntar corazones más o menos enamorados"62, hasta el punto de atribuírsele a ella la responsabilidad del enlace de Isabel II de España y Francisco de Asís.

Todos estos triunfos, unidos a la posesión de una gran fortuna, convertían al duque en un estupendo partido, si no hubiera sido por lo elevado de la edad del mismo. Nacido en el año 1794, tenía más de sesenta años (64) cuando se fue a casar con esta joven, la cual ya debía rondar los treinta63. Había por tanto una diferencia de edad de más de treinta años, algo que posiblemente tampoco fuera tan extraño en esa época.

Juan Valera lo vio satisfactorio y consideraba que aunque el futuro esposo fuera viejo y feo, dadas sus grandes glorias, podría interesar e incluso enamorar a una mujer. Según él, el valor e ingenio de Malakoff serían más seductores que la belleza y, con toda seguridad, su hermana Sofía iría "... más contenta y satisfecha de corazón que si se casara con un mozo elegantísimo y precioso como los señoritos de por ahí"64. Esto decía Juan en respuesta a los escritos de José Freüller, el hermano mayor, el cual no vería con muy buenos ojos este casamiento. Según Juan expresaba a su hermano: "No he podido menos de extrañar la tibieza y poco contento con que han recibido ustedes la nueva del casamiento de Sofía"65.

Unos meses antes el duque de Malakoff, tal y como reseñaba la prensa, había sido enviado a Gran Bretaña como representante de Napoleón III ante la reina Victoria. Este nombramiento de embajador de Francia en el país anglosajón era un esfuerzo por reforzar las relaciones de los dos países y Luís Napoleón, conocedor de la gran valía del duque de Malakoff, le encargaba al mismo dicha empresa66.

El encuentro de la pareja se había producido en el país donde el duque se encontraba destinado, cuando Sofía, formando parte del cortejo, acompañó a Eugenia de Montijo a visitar a la reina Victoria de Inglaterra67. En una fiesta en Windsor, según relata la prensa, el duque de Malakoff “...quedó prendado de la bella española" y le solicitó una rosa que la joven llevaba en la boca, más ella rehusó dársela contestándole que "...lo que sus labios habían besado sólo podía besarlo el que fuese su prometido" 68 . No sabemos lo que contestaría el duque al respecto, lo cierto es que a partir de ese momento se iniciará una relación que al poco tiempo aca-

62 CABAL, J.: La Emperatriz... op. cit., pág. 22.

63 Sofía tenía ya una edad avanzada, según la época, para aún no haber alcanzado el estado matrimonial. No extraña, por tanto, el temor de su madre y hermano a que la joven, a pesar de su gran belleza, pudiera no encontrar esposo y necesitara, por tanto, hacer uso de sus habilidades para ganarse la vida en un futuro.

64 Madrid, 25 de agosto de 1858, Carta de Juan Valera a su hermano José Freüller. Cfr. VALERA, J.: Una anatomía electoral: Correspondencia familiar, 1855-1864, Barcelona, 1992, págs. 66-67.

65 Ibídem, pág. 66

66 La Iberia, 23-04-1858.

67 Otras noticias de prensa nos sitúan sin embargo, el encuentro en Francia, concretamente en los jardines de Saint Cloud, poco después de los triunfos militares del duque en Crimea. Cfr. La Dinastía, 18-8-1889. Sería, por tanto, el mismo lugar donde Winterhalter retrataría a Eugenia de Montijo junto con otras damas de su corte.

68 La llustración Española y Americana, 30-11-1890 
2: artículos Sofía Valera Alcalá-Galiano duquesa de Malakoff...

baría en boda y que causó los más diversos comentarios tanto en París como en España y también entre los miembros de la familia de la joven.

Una vez anunciado el futuro enlace, la familia de Sofía, animada por la condesa de Montijo, inició la búsqueda de todos los papeles que justificaran la nobleza de la joven, como escudos de armas de los Valera, Viaña, Sánchez de Sanz y Paniega, testimonios de hidalguía, expedientes de las distintas ramas, etc... Además comenzaron a intentar reunir dinero para poder dotar a la joven adecuadamente, dada la fortuna del futuro esposo, asunto del que también estaba pendiente la condesa de Montijo69. El padre buscó lo que pudo, pero sobre todo fueron sus hermanos y demás familiares, junto con los miembros de la familia Montijo, incluida la misma Emperatriz, los que fueron con sus regalos proporcionando una fortuna para la joven. Así José Freüller, junto con su cuñado Alonso Caicedo (esposo de Ramona Valera) y el tío Agustín Valera, hermano del padre de Sofía, reunieron con sus presentes un total de 5000 pesetas. Por su parte la Emperatriz le proporcionó unas 15000 pesetas destinadas al ajuar de la joven y se esperaba, además, que le entregaría alguna joya 70 .

La boda, que tendría lugar en París, fue inicialmente prevista para el 8 de septiembre de $1858^{71}$, buscando coincidir el evento con la fecha en que había tenido lugar un año antes la toma de Malakoff, hecho que hizo merecedor al duque del título que ostentaba, pero finalmente se retrasó a la espera de que regresaran los emperadores de Biarritz para asistir a la misma72. Durante el mes de septiembre varios anuncios hacían referencia a la persistencia del retraso de dicha boda hasta que no se produjera el esperado regreso de Eugenia y Napoleón III73.

Finalmente, el deseado evento tuvo lugar en octubre. El día concreto no queda muy claro pues en una de las noticias, aparecida el día 17 de octubre en la prensa, se habla de un contrato matrimonial el martes 12 de octubre y de la celebración el día 15 de dicho mes, siendo el matrimonio civil a las cinco de la tarde y a las nueve de la noche el religioso en la capilla del Palacio de Saint Cloud74, presidido por el arzobispo de Nancy. Días más tarde se inserta una nueva noticia venida de París con fecha 14 de octubre que indica que el día anterior se había verificado el enlace del duque de Malakoff con Sofía Valera, lo que nos llevaría a ubicar el acontecimiento en el día 13 de octubre. En esta última se nos indicaba la asistencia de los emperadores al enlace junto con toda su familia, además de ministros y altos dignatarios. De hecho, los testigos del duque de Malakoff fueron los ministros de Estado

69 Todo el proceso aparece expuesto en las cartas que Juan Valera envía a sus distintos familiares y a la propia Sofía. VALERA, J.: Correspondencia, vol. I... op. cit., págs. 580-590.

70 Ibídem, pág. 587.

71 VALERA, J.: Una anatomía... op. cit., pág. 65. Erróneamente SÁENZ DE TEJADA BENVENUTI en las notas de la obra VALERA, J.: Cartas íntimas... op. cit., pág. 45, nota 2, nos indica que el enlace tuvo lugar el 22 de agosto de 1858, lo que hemos podido ver que no sucedió.

72 VALERA, J.: Cartas intimas... op. cit., pág. 45.

73 CASILARI, S.: El Avisador Malagueño, 10-09-1858 y 25-09-1858.

74 La Iberia, 17-10-1858.

75 La Iberia, 20-10-1858. 
y de Guerra, mientras que de Sofía lo serían el ministro Fould, embajador de España en Francia y el banquero marqués de Casa-Riera. Además, nos informa de que fue el arzobispo de Nancy el que ofició el acto75.

Tras el enlace, el matrimonio se desplazó a su residencia en París, en la avenida Marceau 76 . Desde allí, Sofía, en abril de 1859, recibiría las noticias de la enfermedad y fallecimiento de su padre José Valera. Cinco meses después, la joven, acompañada de su esposo, se desplazaba a España para visitar a sus familiares, a los cuales no había visto desde la perdida del patriarca. Según indicaba la prensa, primeramente el duque de Malakoff, acompañado de Sofía, acudiría a Madrid para que éste fuera presentado a la reina de España y, desde aquí, se desplazaría a Andalucía a ver a la familia de Sofía. Su hermano Juan, por estas fechas, se encontraba en Doña Mencía, mientras la madre parecer ser que se alojaba en Málaga en compañía de su hijo José77. La correspondencia de su hermano nos vuelve a dejar constancia de este evento, al indicar a su hermano José Freüller que se encontraba en Doña Mencía intentado ver la manera de enviar a la madre algún dinero "para que reciba comm'il faut a los mariscales"78.

En este viaje Sofía ya debía estar embarazada, pues seis meses más tarde, el 13 de marzo de 1860, tenemos noticias de que la joven había tenido un parto muy difícil y doloroso. Del mismo nació su única hija, la cual sería llamada Luisa Eugenia, en honor del Emperador Luís Napoleón y la Emperatriz Eugenia, ambos padrinos de la recién nacida79. Según algunas fuentes, quizás erróneamente, el nacimiento se producía en África, concretamente en Argelia, lugar donde el duque de Malakoff será enviado como gobernador general. Pero si nos fiamos de los escritos de Juan Valera, será en París donde la joven venga al mundo.

Fueron pocos los años que el duque disfrutó de su hija, pues fallecía en Argel en junio de 1864, dejando a Sofía viuda y con una considerable fortuna para subsistir, además de residencias diversas, como la existente en Biarritz, donde Sofía acudirá en épocas estivales o la quinta que tenía en Villerville, Normandía ${ }^{80}$. La hija se educará en un entorno privilegiado, teniendo como amigos de infancia al hijo del Emperador de Francia y al futuro rey de España, Alfonso XII. Dos años más tarde, Sofía sería galardonada por parte de la reina con la Banda de la Real Orden de Damas Nobles de la Reina María Luisa, mostrando así el aprecio que sentía hacia la misma81.

Pero esta hija fue, a su vez, un motivo de desgracias para Sofía, dado que

76 SAENZ DE TEJADA, Carlos: “Análisis de esta correspondencia”, en VALERA, Juan: Cartas íntimas...op. cit., pág. 25.

77 La Iberia, 07-09-1860.

78 VALERA, J.: Correspondencia, vol. I... op. cit., pág. 631. Se trata de una carta escrita desde Doña Mencía por Juan Valera a su hermano José Freüller el 3 de septiembre de 1859, siendo seis días más tarde la noticia de la prensa de la inminente venida a Andalucía de los duques de Malakoff.

79 Ibídem, págs. 659-661.

80 VALERA, J.: Correspondencia, vol. V (1888-1894), Madrid, Castalia, 2005, pág. 72.

81 (A)rchivo (H)istórico (N)acional, Signatura ESTADO, 7570, Exp. 73, Exp. de Nombramiento de la Orden de Damas Nobles de la Reina María Luisa de Sofía Valera Alcalá Galiano, Duquesa Viuda de Malakoff, 1-12-1866. 
contraería matrimonio con un conde polaco, Zamoyski, el 10 de marzo de 1881 en San Felipe du Roule, y el esposo se dedicaría a dilapidar la fortuna familiar y, además, a maltratar a la joven, tanto verbal como físicamente, amenazando incluso a su propia suegra 82 . Por tanto, se inició una dura lucha por conseguir la nulidad del matrimonio, desde marzo de 1885, para lo cual Sofía y su hija acudieron incluso al mismo Vaticano para pedir al Papa León XIII que intercediera por ellas ${ }^{83}$. También la misma reina Isabel II intervino para apoyar a la joven, al igual que otras altas personalidades del mundo eclesiástico (arzobispo de Sevilla, cardenal Benavides, cardenal González, etc. $)^{84}$. El hecho fue tan penoso que incluso Sofía se refugió con su hija en un convento ${ }^{85}$, huyendo del temido esposo. Finalmente, en febrero de 1888 , la prensa se hacía eco de que dicha unión había quedado definitivamente rota86, lo que también era relatado por su hermano Juan en carta de felicitación a su hermana 87.

Otra de las desgracias que tuvo que padecer fue la muerte de su madre, $\mathrm{M}^{\mathrm{a}}$ Dolores Alcalá Galiano, en fatídicas circunstancia. En junio de 1872, tras varias peticiones de sus hijos, la marquesa se traslada a París para pasar el verano en compañía de su hija Sofía. Mas lo único que encontró la joven fue la llegada del cuerpo calcinado de su madre, tras haber sufrido un accidente el tren en que viajaba, al chocar contra otro en Juvisy (localidad ubicada a unos 18 kilómetros de Paris) e incendiarse 88 . La noticia fue pronto difundida por la prensa que narraría la crudeza de los hechos y los posteriores funerales que en honor de la dama se celebraron en París ${ }^{89}$.

Durantes todos estos años que discurren desde el fallecimiento del duque, Sofía seguirá realizando viajes a España para visitar a su familia90 o a la condesa de Montijo ${ }^{91}$ a la que acompañó durante algunos periodos en la ya citada villa de Carabanchel ${ }^{92}$ y también visitaría en 1879 para verla antes de su fallecimiento 93 También fueron frecuentes sus estancias en Saint Cloud, acompañando a Eugenia de Montijo y a las numerosas damas que formaron parte de su Corte ${ }^{94}$ [4].

82 VALERA, J.: Correspondencia, vol. IV (1884-1887), Madrid, Castalia, 2005, pág. 228.

83 VALERA, J.: Cartas intimas... op. cit., págs. 32, 232, 234, 237-238, 254, 256, 258, 265, 270 y ss. VALERA, J.: Correspondencia, vol. IV...op. cit., pág. 587. En carta a Francisco Moreno, el 28 de noviembre de 1886, Juan Valera le indicaba que Sofía se encontraba en Roma.

84 Ibídem, pág. 629.

85 Ibídem, pág. 380. La llustración Española y Americana, 30-11-1890, pág. 326

86 La Dinastía, 29-02-1888.

87 VALERA, J.: Correspondencia, vol. V... op. cit., pág. 25. El 20 de febrero de 1888 se gano la sentencia. El esposo apelará, pero nuevamente el 8 de julio Juan Valera indica que de nuevo el resultado ha sido favorable para su sobrina.

88 (A)rchivo (N)otarial de (C)abra, Escribanía de Tomás Vergara cubero, $n^{\circ}$ de protocolo 128, 1872, fol. 593. Traducción de la Diócesis de París.

89 La llustración Española y Americana, 1de julio de 1872, pág. 386. El Avisador Malagueño, 25-06-1872.

90 En 1881 tenemos constancia de una larga estancia en Lisboa, acompañando a su hermano Juan. VALERA, J.: Correspondencia, vol. III (1876-1883), Madrid, Castalia, 2004, pág. 335.

91 En 1866 la prensa deja constancia de una de esas visitas, tras haber pasado un tiempo en Biarritz en compañía de su hermana Ramona, duquesa de Caicedo. Lloyd Español, 13-09-1866.

92 Juan Valera informa en sus escritos de alguna de esas visitas. VALERA, Juan: Correspondencia, vol. II...op. cit., págs... 274, 433. Carta del 6 de octubre de 1866.

93 VALERA, J.: Correspondencia, vol. III...op. cit., pág. 177. 


\section{Q: artículos Eva María Ramos Frendo}

Tras una vida definitivamente consagrada a su única hija, Luisa Malakoff, Sofía Valera fallecería en noviembre de 1890 a consecuencia de una pulmonía que degeneró en tifus ${ }^{95}$. La prensa, como en otras ocasiones, se hizo eco de la noticia y consagró espacio de sus páginas a exaltar a la fallecida y a relatar algunas de las tragedias que había padecido ${ }^{96}$.

Así finalizaba la vida de la que fue considerada una de las bellas damas del Segundo Imperio, una de aquellas "...caras bonitas" que rodearían a Eugenia de Montijo en su residencia de las Tullerías, uniéndose a su nombre otros como la condesa de Castiglione, la princesa de Metternich-Sandor, esposa del embajador de Austria en Francia, la princesa Matilde, hija del rey de Westfalia y gran protectora de las artes, que nos es descrita como gran artista y escritora, la condesa de Bedoyére, la condesa de la Poéze, la condesa de la Beaulaincourt, la condesa de Pourtalés, la duquesa de Morny, la duquesa de Colonna, una destacada escultora que trabajaba bajo el pseudónimo de Marcello, la condesa de Mercy-Argenteau, Madama de Rute, ésta dedicada a los retratos en miniatura ${ }^{97}$.

La pregunta que se nos plantea es si verdaderamente existió una vocación artística en la joven, dado que, tras el fallecimiento del esposo, quedó con unas circunstancias sumamente propicias para volver a cultivar su afición de la juventud. Tenía tiempo y fortuna para vivir sin preocupaciones, la considerada como única situación para que una mujer pudiera dedicarse a la pintura u otras actividades 98 . Además, como hemos podido observar, en París se vería rodeada, dentro de la corte imperial, de otras muchas jóvenes que compartían idénticas inquietudes artísticas (escultura, pintura de miniaturas, música, etc.), lo que sería un estímulo añadido. Pero, sin embargo, en la correspondencia de su hermano, donde ambos intercambiaban todas sus vivencias e inquietudes, no aparece ni la más mínima mención al desarrollo de esta actividad.

Todo esto nos lleva a suponer que el interés de Sofía por la pintura debió ser sobre todo motivado por el temor de que, pasado el tiempo, no encontrara un marido y debiera ella ganarse la vida por sus propios medios, dada la frágil fortuna familiar. Mas una vez contraído el matrimonio y viéndose libre de esos temores abandonaría el cultivo de esta actividad para la que, según palabras de su hermano, se encontraba tan dotada. Al menos, si nuevos documentos no indican algo diferente, las fuentes con las que contamos nos llevan a mantener la citada hipótesis.

94 VALERA, J.: Correspondencia, vol. II...op. cit., pág. 328.

95 VALERA, J.: Correspondencia, vol. V...op. cit., pág. 298. . La Ilustración Española y Americana, 30-111890 , pág. 326

96 La llustración Española y Americana, 30-11-1890, pág. 326. La Dinastía, 23-11-1890.

97 IVIMY, Alicia M.: "Las damas del Segundo Imperio", Por esos mundos, 01-11-1907, pág. 424. Se describe a Sofía como "un tipo de belleza andaluza...". Se trata de un artículo que habla sobre un libro que con dicho título, Las damas del Segundo Imperio, había publicado en Francia M. Federico Loilée

98 Estrella de Diego nos indica que las mujeres de solteras estaban sometidas a los padres, de casadas a los maridos y de huérfanas a un tutor que controlaría su fortuna. Por tanto, sin un patrimonio propio sólo "...en caso de enviudar, macabro acontecimiento que les dejaba tiempo libre y cierta disponibilidad si eran afortunadas..." podrian dedicarse con total libertad a la pintura. Cfr. DIEGO, Estrella de: La mujer y...op. cit., pág. 215. 